\title{
Development of a Hazard Evaluation Technique for Earthquake-Induced Landslides Based on an Analytic Hierarchy Process (AHP) (IPL-154)
}

\author{
Daisuke Higaki, Eisaku Hamasaki, and Kazunori Hayashi
}

\begin{abstract}
In this study, we developed a hazard evaluation technique for earthquake-induced landslides that is based on topographical and geological factors extracted by an analytic hierarchy process (AHP). Several past earthquake cases that have caused multiple landslides in Japan were analyzed. With this method, through buffer movement analysis, we were able to obtain factor data on the respective sizes of terrain impacted by landslides and the magnitude of the landslides in the target area. In addition, we incorporated a method to provide predictive values for the evaluation through blunder probability analysis. The area distribution of the coherent landslides following the Mid-Niigata Prefecture Earthquake in 2004 corresponded well with the high-scoring areas derived by our evaluation model. This paper presents the results of the IPL project (IPL-154) titled "Development of a methodology for risk assessment of the earthquake-induced landslides".
\end{abstract}

\section{Keywords}

Earthquake-induced landslide - AHP (analytic hierarchy process) $\bullet$ Hazard $\bullet$ Landslide susceptibility map

\section{Background and Objectives}

Landslides are a type of natural disaster that can be triggered by earthquakes, and these slides occur along destabilized slope areas. In recent years, researchers have analyzed the topography and geology, as well as the conditions related to seismic motion, in several areas where earthquake-induced landslides have occured (e.g., Keefer 1984; Rodríguez et al. 1999; Yagi

D. Higaki $(\bowtie)$

Hirosaki University, Faculty of Agriculture and Life Science,

Bunkyo-Cho 3, Hirosaki, 036-8561, Japan

e-mail: dhigaki@hirosaki-u.ac.jp

E. Hamasaki

Advantechnology Co., Ltd. Aoba-Ku Kakyoin 1-4-8,

Sendai, 980-0013, Japan

e-mail: hamasaki@advantechnology.co.jp

K. Hayashi

Okuyama Boring Co., Ltd. Aoba-Ku Futsukamachi 13-18

, Sendai, 980-0802, Japan

e-mail:k.hayashi@okuyama.co.jp

(C) The Author(s) 2017

K. Sassa et al. (eds.), Advancing Culture of Living with Landslides, DOI 10.1007/978-3-319-59469-9_34 et al. 2009). Earthquakes are frequent events in Japan, and The Japan Landslide Society has developed a method for earthquake-induced landslide hazard zoning based on local topographic and geological conditions (Higaki et al. 2015).

This study was aimed at the development of a method for hazard zoning roughly at a scale of a 1:50,000 topographic map, rather than seismic risk evaluations at the scale of individual slopes. An evaluation at such a scale can be utilized as the basis for forecasting seismic damage in a given area, or for creating disaster mitigation plans. In this paper, we provide an overview of the proposed method, as well as the results yielded from the application of this method to landslides caused by the Mid Niigata Prefecture Earthquake in 2004.

\section{Methodology of Hazard Zonation}

In recent years, much research has been conducted on evaluation methods for identifying landslide-prone hazardous areas. This work typically involves performing 
statistical analyses on the geographic characteristics of landslide-prone areas and displaying the data with a geographic information system (GIS). The analytic hierarchy process (AHP) has been frequently used for landslide hazard mapping, as it can incorporate both quantitative and qualitative factors as part of the evaluation; then, expert opinions are used to score the relative importance of those factors (e.g., Kamp et al. 2008; Yalcin et al. 2011; Miyagi et al. 2014).

The Japan Landslide Society has summarized the characteristics of many landslides caused by past earthquakes in Japan (The Japan Landslide Society 2012), and the distribution of landslides caused by the 2011 Great East Japan Earthquake were recently added to this database (The Project team for Collaborative Research and Development of River and Erosion Control, Japan Landslide Society 2013); by referencing prior studies for relevant characteristics and upon brainstorming among experts. This work has revealed the topographical and geological conditions that are most prone to disruptions that will initiate landslides following earthquakes (Figs. 1 and 2). The key findings can be

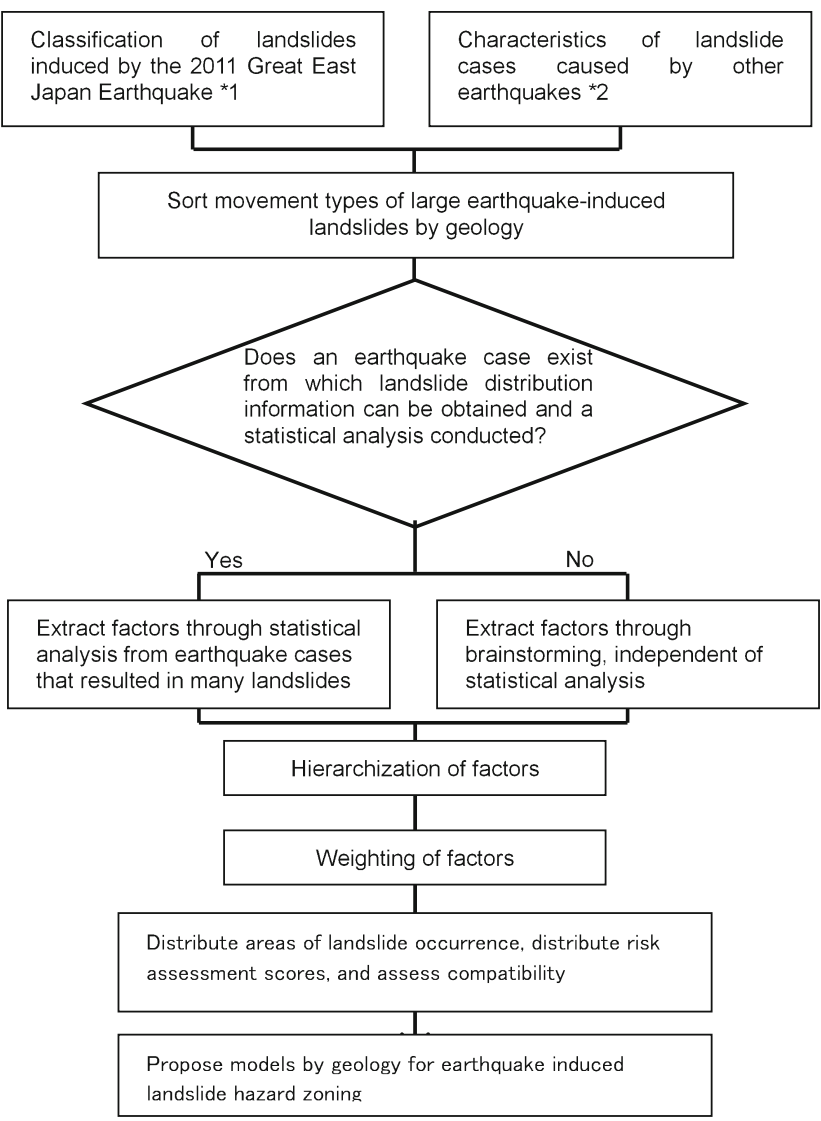

Fig. 1 Research flow chart (Higaki et al. 2015). *1 The Project team for Collaborative Research and Development of River and Erosion Control, Japan Landslide Society (2013), *2 The Japan Landslide Society (2012) summarized as follows: shallow disrupted landslides are particularly likely to occur during earthquakes; coherent landslides occur more often in geological terrain from or after the Neogene period; large-scale disrupted landslides occur more often in geological terrain from or before the Paleogene period and mainly in accretionary prisms. In addition, large-scale disrupted slides and shallow disrupted landslides have occurred frequently in the hills covered in volcanic ash deposits from the Quaternary period (Sugimoto et al. 2012).

In this study, we conducted GIS statistical analyses with respect to topographical and geological factors on the following earthquakes that caused multiple landslides: the Tokachi-Oki Earthquake in 1968, Izu-Ohshima Kinkai Earthquake in 1978, Western Nagano Prefecture Earthquake in 1984, the Mid Niigata Prefecture Earthquake in 2004, and the Iwate-Miyagi Nairiku Earthquake in 2008. On the basis of these results, we constructed a hazard zoning model by using the AHP (Fig. 3). Next, we evaluated the factors contributing to the spatial spread based on a scale that matched the area of landslide occurrence or the degree of the slopes.

We also incorporated buffer movement analysis (Hamasaki et al. 2015) in order to create GIS data that takes scale into account. In addition, in reality, many landslides occur in places with high evaluation scores; thus, to increase the predictive values of the evaluation, scores should be allocated by factors to create a wider gap in evaluation points between slopes where landslides do and do not occur. To achieve this, we incorporated blunder probability analysis (Hamasaki et al. 2015; Hayashi et al. 2015).

\section{Factor Data Creation and Weighting of Factors - a Sample Study of the Deep-Seated Coherent Landslides Caused by the Mid Niigata Prefecture Earthquake in 2004}

\section{Distribution of Landslides and Obtaining Factor Data}

In this section, we discuss the case study of the Mid Niigata Prefecture Earthquake in 2004. Following this earthquake, the distributions of shallow disrupted landslides and coherent landslides were characterized (Yagi et al. 2009). By referencing past studies, we identified the following seven factor categories with regard to coherent landslides: (1) slide potential, (2) ease of shaking during an earthquake, (3) erosion potential at the toe of slopes, (4) water collectability, (5) geology, (6) reduction in ground strength, and (7) geological structure (Hayashi et al. 2015). To calculate the topographical sizes, $10 \mathrm{~m}$ mesh elevation data were used 


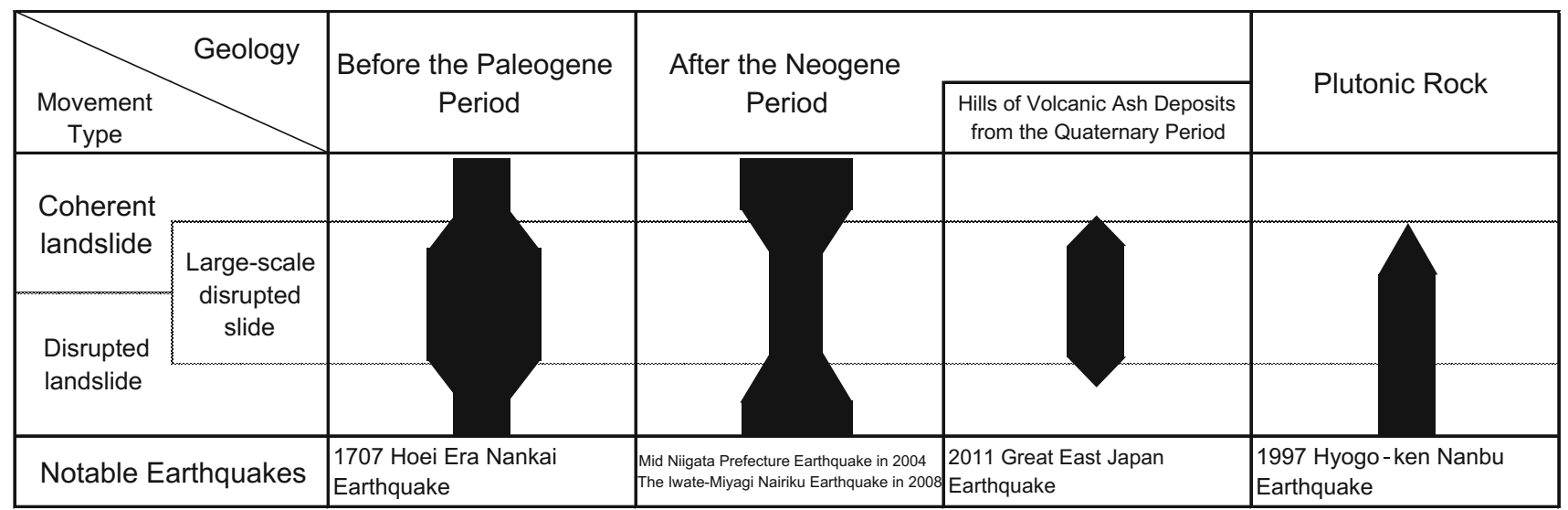

Fig. 2 Types of landslides that have occurred following past earthquakes in Japan, and geological regions prone to each (Higaki et al. 2015)

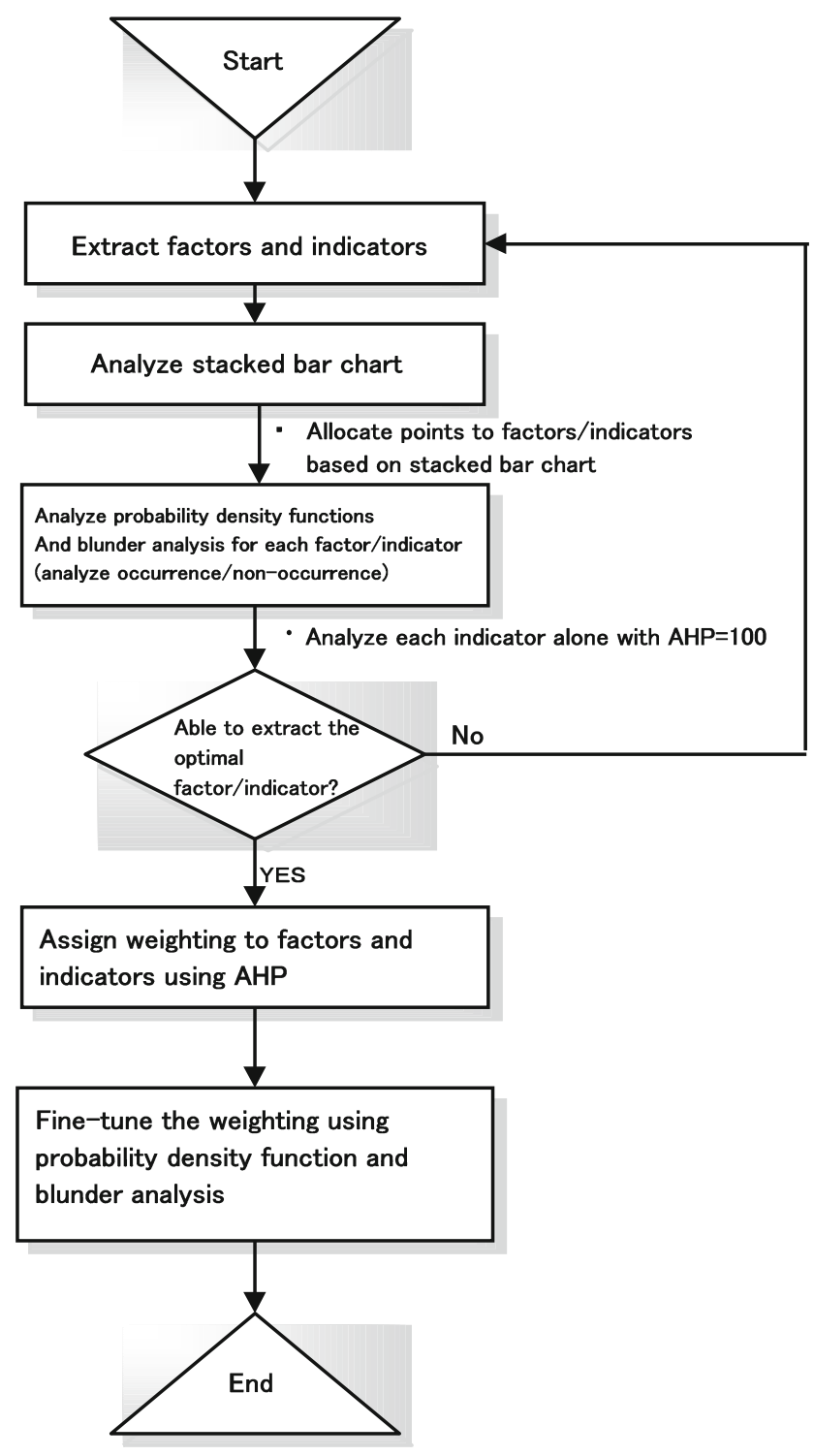

Fig. 3 Flow chart for developing the methodology for earthquake-induced landslide hazard zoning using AHP
(Map of Hokkaido, GIS MAP Terrain; hereinafter referred to as DEM). We used slope in factor (1). In factor (2), since convex slopes are prone to amplify seismic motion, we used the convex-concave index. Here, the convex-concave index (Hamasaki et al. 2015) refers to the value obtained by dividing by distance $\mathrm{d}$, the absolute value of the differences between the central altitude and the eight mean altitudes located a specified distance " $\mathrm{d}$ " in eight directions from the target mesh. This value indicates the degree of relief in the periphery of the target mesh. In factor (3), we used overground-openness as an indicator, since sloped surfaces become unstable if the slope edges are susceptible to erosion. Overground-openness (Yokoyama et al. 1999; Fig. 4) was calculated as the average of the values taken from each of the eight directions as follows: at a given point located on the terrain cross section within a specified distance $(\mathrm{L})$ of the target mesh, subtract the maximum value of the angle of elevation from the vertical $90^{\circ}$ upward angle. The value becomes smaller as it moves to deep valleys with advanced erosion.

Hydrological conditions during earthquakes are important factors to consider when evaluating landslide occurrence

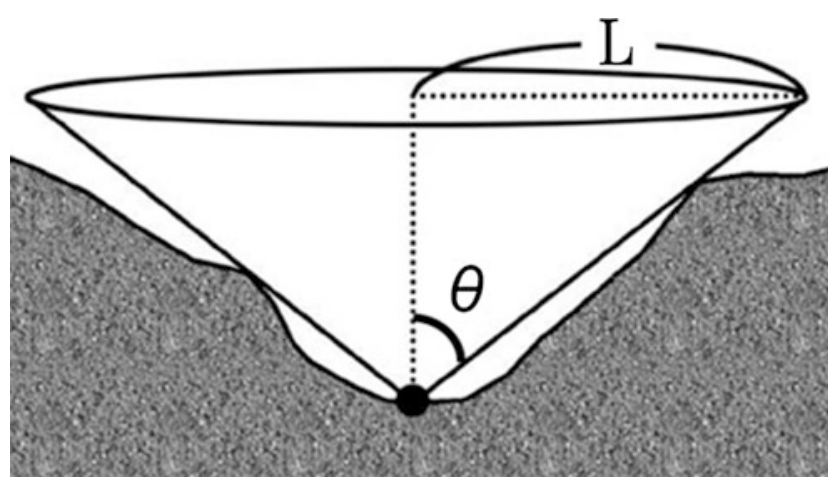

Fig. 4 The measurement of overground-openness in a given location (Yokoyama et al. 1999). Set $\mathrm{L}$ and solve for $\theta$ as shown in the figure 
(Chigira et al. 2012). Thus, in factor (4), we calculated the Topographic Wetness Index, which reflects the topographical water collectability (Beven and Kirkby 1979).

Slope material is also an important factor for landslide occurrence. In factor (5), we used seven lithological classifications to characterize the slope material; this scheme roughly categorizes the geology of Japan by the sliding resistance force (Hamasaki et al. 2015). We re-classified the geological portion of the 1:50,000 numerical geologic map (Takeuchi et al. 2004) and converted it to data for the $10 \mathrm{~m}$ mesh. As many coherent landslides from the Mid Niigata Prefecture Earthquake in 2004 occurred within landslide bodies that had less strength compared to bedrock (Has et al. 2012), we divided the target mesh into those points located in the relevant landslide body and those that were not, and this information was used as the indicator for (6). In (7), due to the fact that sedimentary rocks developed in the bedding planes resulted in numerous large-scale coherent landslides along slopes with a dip slope structure (Hayashi et al. 2015), and that numerous shallow disrupted slides occurred in anti-dip slopes (Yagi et al. 2005), we calculated the difference between the tilt directions of the slope and stratum $(\beta)$ and the visual tilt angle of the strata in the tilt direction of the slope $(\gamma)$. These were divided and used in the $10 \mathrm{~m}$ mesh.

The data for the GIS statistical analysis were collected by deriving the landslide area ratio as the ratio of mesh including landslides within each buffer to the in-buffer mesh, while moving the circular buffer of a fixed search radius (R) (circle shown in Fig. 5) sequentially in one direction. At the same time, we obtained the above-mentioned topographical and geological factor data in each buffer. Then, while keeping the

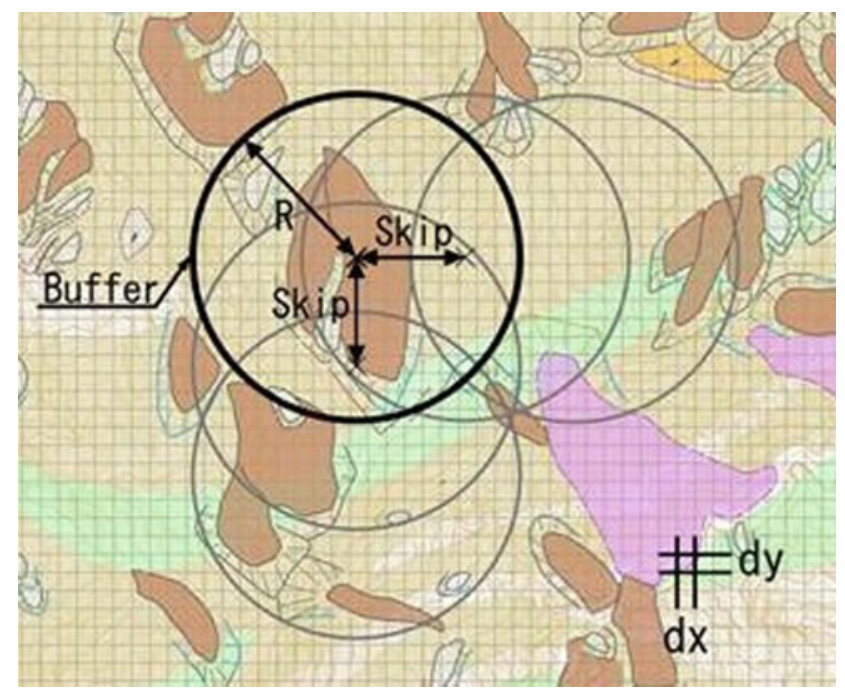

Fig. 5 Methodology for buffer movement analysis (Hamasaki et al. 2015). The brown colored area represents the landslide occurrence area and the background is the distribution of the numerical topographical/geological data buffer at a constant distance and moving from each in one direction so as to not create gaps, we gathered data in the target area. The above-described method is referred to as buffer movement analysis (Hamasaki et al. 2015). At this point, for the search radius (R), we set the buffer size so that it contained the majority of the area where coherent landslides or shallow disrupted landslides have occurred. In the case of coherent landslides, we set $\mathrm{R}=250 \mathrm{~m}$.

\section{Weighting the Factors}

Next, we sorted the data gathered in the buffer movement analysis into occurrence data, which included both landslide occurrence data and nonoccurrence data. Taking as an example the factors that can be expressed by rank, it can be said that a particular rank is closely connected to the landslide occurrence if a larger landslide area ratio increases the ratio of that certain rank within the factor. Thus, we determined the total buffer count for each landslide area ratio for a given factor. If the ratio of a given rank within the buffer count increased as the landslide area ratio increased, we gave a higher weighting to that rank. Conversely, if the ratio of the rank decreased with a larger collapse area ratio, the rank was considered to contribute less to the collapse and was assigned a smaller score. To perform this task visually, we created a stacked bar chart as displayed in Fig. 6. Using Fig. 6, we will walk through the example of the slopes where landslides occurred. The landslide area ratio was divided into six levels, five of which were broken up into $10 \%$ intervals between 0 and $40 \%$ and the last level consisted of $40 \%+$ data. If we view the ratio of the slope rank for each $5^{\circ}$ in the stacked bar chart, we can determine that

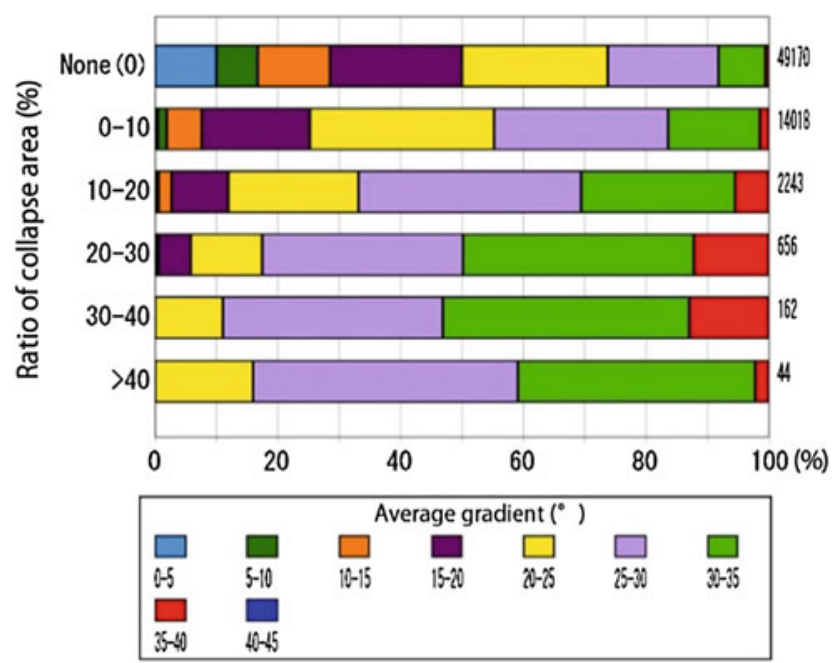

Fig. 6 Stacked bar chart showing changes in occupancy rate by slope rank and landslide area ratio (the numbers to the right of the bar chart are the total number of buffers by landslide area ratio) 


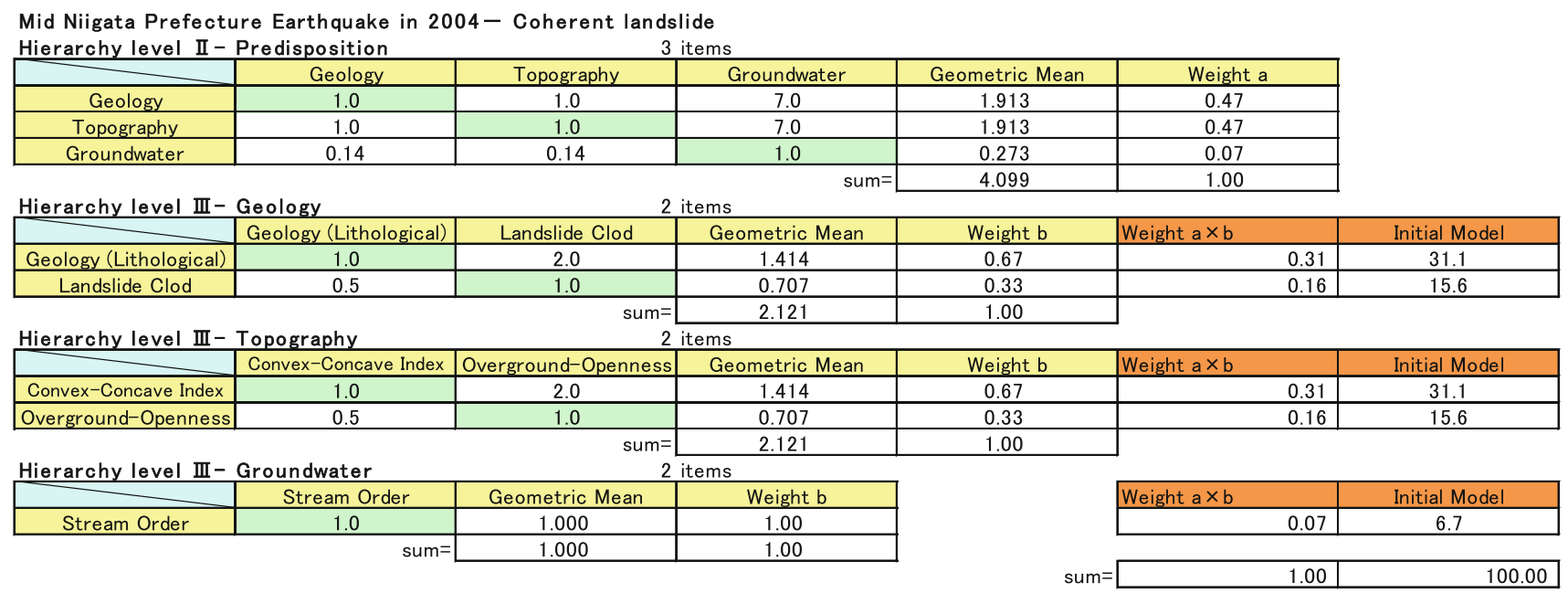

Fig. 7 AHP hierarchy and weighting of topographical, geological, and groundwater factors in a paired comparison

collapses are more likely to occur in slopes of $30^{\circ}$ or more. Between $25^{\circ}$ and $30^{\circ}$, we observed a slight upward trend in the buffer count, but conversely between $15^{\circ}$ and $25^{\circ}$, there was a downward trend. Below $10^{\circ}$, the buffer count decreased as the landslide area ratio increased, so the score allocation was small. Thus, we allocated the following weights to the data: 1.0 for $30^{\circ}$ or more, 0.6 to $25^{\circ}-30^{\circ}, 0.3$ to $15^{\circ}-25^{\circ}$, and 0.1 to $15^{\circ}$ or less.

The factor data described above are values that can be numerically rank classified. Qualitative factors such as the geological classification were represented by the mode of the mesh counts in the buffer. Additionally, we binarized whether the buffers include or not include the body of old coherent landslides.

On the other hand, the relative weighting between each factor was determined by a paired comparison and through brainstorming work (Fig. 7). To determine the first-level factors most responsible for causing coherent landslides induced by earthquakes, we selected all the geological, topographical, and groundwater factors and assigned weightings for each. Since the coherent landslides were caused by earthquakes rather than rainfall, the groundwater weighting was assigned at $1 / 7$ of the other two factors. In addition, for geological factors, it was shown that at one rank lower in the factor hierarchy, lithological factors (rock type) were the most important, while the presence of a body of the coherent landslide contributed to secondary landslides. For this reason, it was assigned $1 / 2$ in the weighting. Among the topographical factors were the convex-concave index and overground-openness. The groundwater was assumed to be related to the stream order for a given location.

Through the hierarchical structure and process of factor weighting described above, AHP evaluation scores were calculated for any location where relevant data could be obtained.

\section{Study of the Optimal Model Based on Blunder Probability}

In order to achieve the optimal model, we evaluated the degree to which the factors were relevant to coherent landslides or shallow disrupted slides using blunder probability analysis (Hamasaki et al. 2015). First, we sorted the frequency distribution of the evaluation scores within the target range into landslide occurrence and nonoccurrence data and compared the two after approximating their frequency distribution to the normal distribution (Fig. 8). After determining the mean score, we set the mean score of each as the threshold. We then determined the proportion of

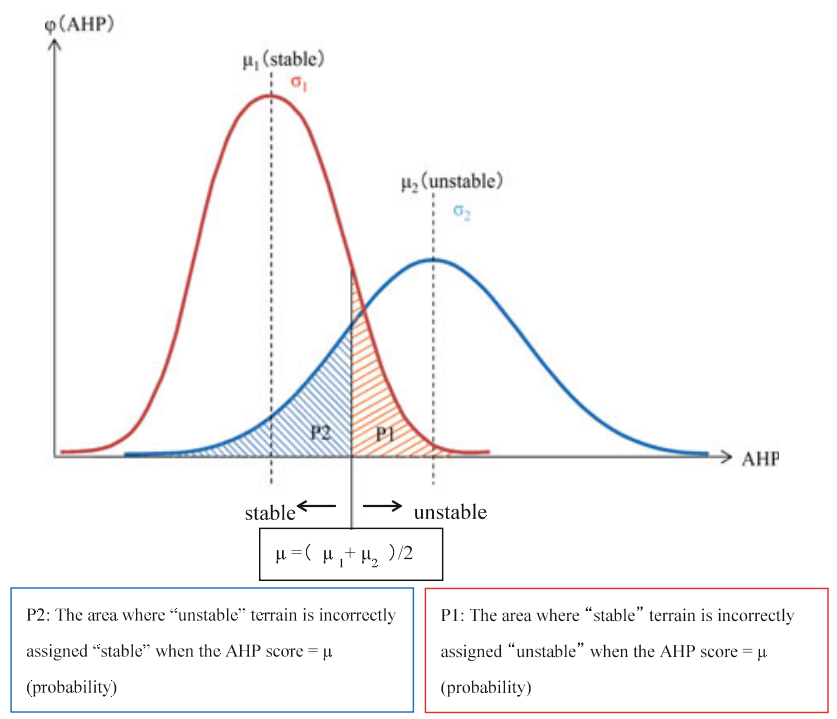

Fig. 8 Approximation using the normal probability density function and compatibility assessment using the blunder probability (P) (Hamasaki et al. 2015) 
Fig. 9 AHP score distribution in the target area during Mid Niigata Prefecture Earthquake in 2004 and score distribution in occurrence/nonoccurrence areas for deep-seated coherent slides

\begin{tabular}{|c|c|c|c|c|c|c|}
\hline Item & $\begin{array}{c}\text { Geology } \\
\text { (Lithological) }\end{array}$ & Landslide Body & $\begin{array}{l}\text { Convex-Concave } \\
\text { Index }\end{array}$ & $\begin{array}{l}\text { Overground } \\
\text {-Openness }\end{array}$ & Stream Order & \\
\hline Weight & 30 & 20 & 25 & 15 & 10 & \\
\hline \multicolumn{3}{|c|}{ Nonoccurrence } & \multicolumn{3}{|c|}{ Occurrence } & $\begin{array}{l}\text { Blunder } \\
\text { probability }(\mathrm{P})\end{array}$ \\
\hline$\mu 1$ & $\sigma 1$ & $\mathrm{p} 1$ & $\mu 2$ & $\sigma 2$ & $\mathrm{p} 2$ & $(p 1+p 2) / 2$ \\
\hline 60.9 & 25.5 & 0.378 & 76.7 & 22.4 & 0.362 & 0.370 \\
\hline
\end{tabular}

$\mu$ :Mean $\sigma: S D \quad p:$ probability

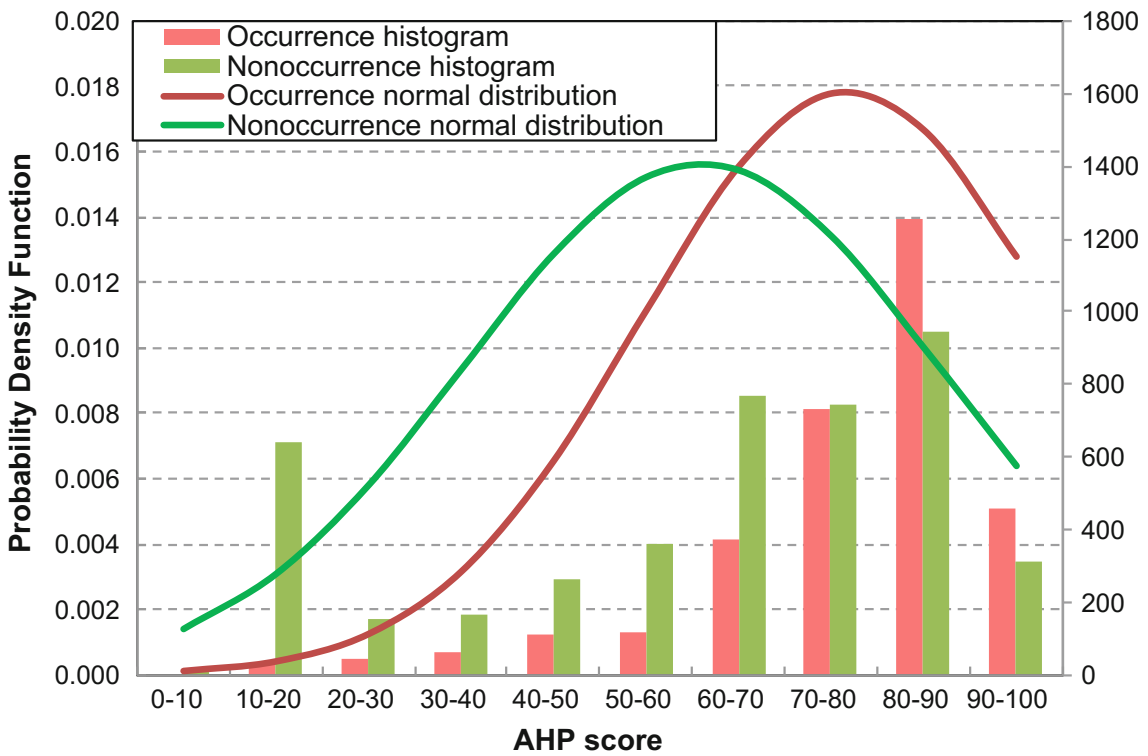

nonoccurrence data that fell higher than that score (P1) and the proportion of occurrence data that fell lower (P2). The blunder probability $\mathrm{P}$ was defined as the average of $\mathrm{P} 1$ and $\mathrm{P} 2$. It can be said that a smaller P signifies a good model that can better separate occurrence and non-occurrence data.

We evaluated the coherent landslides caused by the 2004 Niigata-Chuetsu Earthquake by adjusting the allotted points to the five factors shown in Fig. 9. We were able to slightly reduce $\mathrm{P}$ in comparison to the initial model by allocating scores as shown in the table in Fig. 9.

\section{Applicability of AHP Risk Evaluation Results}

In the final evaluation model described above, we viewed the distribution of AHP scores and occurrences of deep-seated slides during the Mid Niigata Prefecture Earthquake in 2004
(Fig. 10). We were able to see that the Imo River basin area, where large-scale coherent landslides had been re-activated and landslide dams were formed, had a concentration of high scores that were 80 points or more (Fig. 10).

\section{Conclusions}

On the basis of data from past studies that investigated multiple landslide events following large earthquakes in Japan, and through the application of GIS statistical analyses, we have proposed a method for earthquake-induced landslide hazard zoning that employs an AHP. In this study, we used the 2004 Mid Niigata Prefecture Earthquake in 2004 as an example to evaluate the proposed method. The distribution data for coherent landslides were used to conduct a factor analysis of the key features related to landslide occurrence, and data 
Fig. 10 Distribution of AHP scores and landslides in and around the Imo River basin following Mid Niigata Prefecture Earthquake in 2004

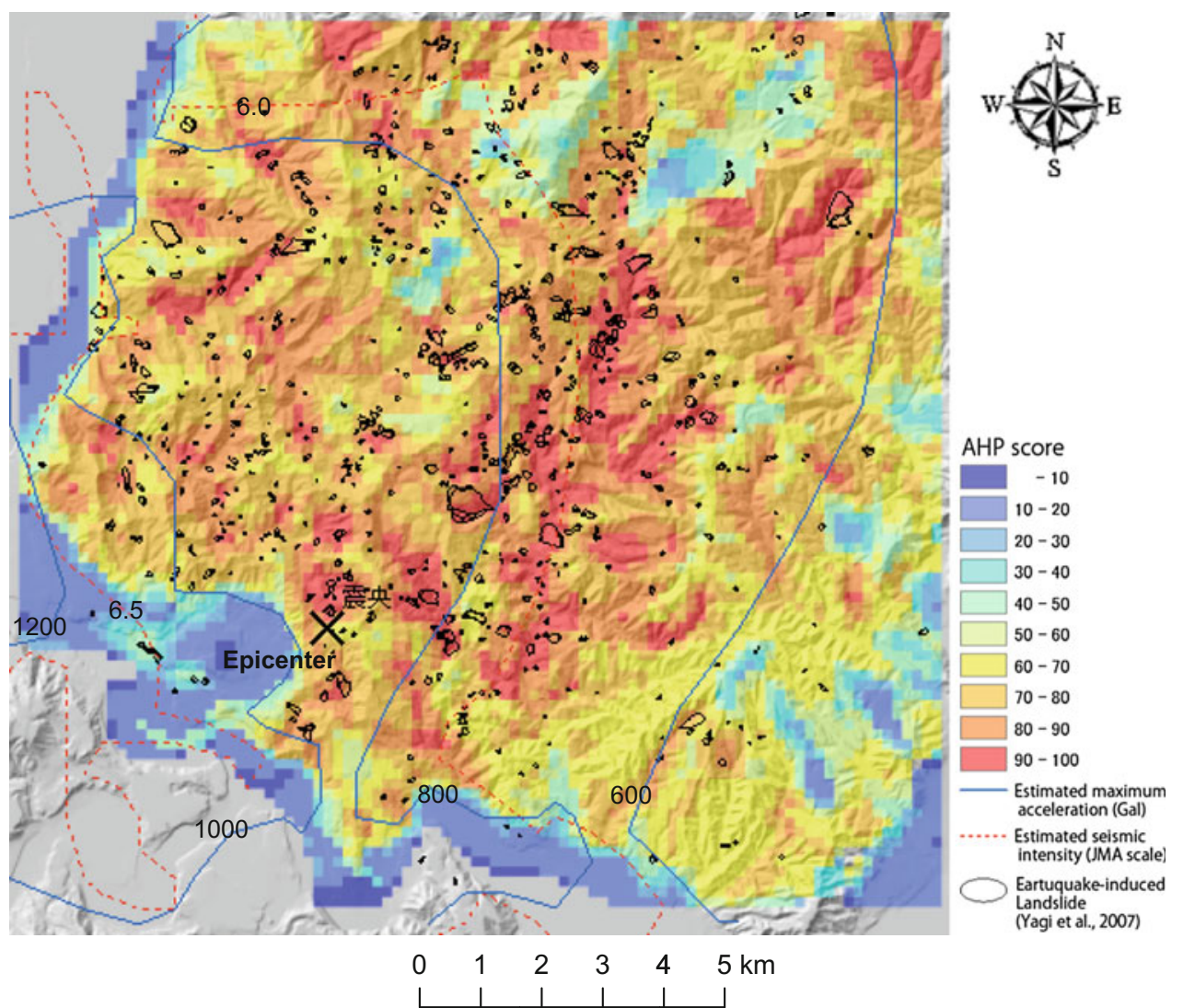

acquisition was achieved through buffer movement analysis. In addition, we improved the evaluation model through blunder probability analysis. As a result of the verification, the methodology described above was shown to be effective as a topographical and geological approach to identify earthquake-induced landslide hazard areas.

Acknowledgements This research was part of the following projects: "Research and Development Efforts for River and Erosion Control" at the Ministry of Land, Infrastructure, and Transport; "Create a Methodology to Evaluate Earthquake-Induced Landslide Hazard Areas based on Typology," which was conducted during the 2011-2013 fiscal year. These initiatives were commissioned by the National Institute for Land and Infrastructure Management (NILIM) through the Japan Landslide Society. We express deep gratitude to the supporters of the relevant organizations.

\section{References}

Beven KJ, Kirkby MJ (1979) A physically based, variable contributing area model of basin hydrology. Hydrol Sci Bull 24(1):43-69

Chigira M, Nakasuji A, Fujiwara S, Sakagami M (2012) Catastrophic landslides of pyroclastics induced by the 2011 Off the Pacific Coast of Tohoku Earthquake. Earthquake-Induced Landslides: Proceedings of the International Symposium on Earthquake-Induced Landslides. Kiryu, Japan. pp 139-147
Hamasaki E, Higaki D, Hayashi K (2015) Buffer movement analysis and blunder probability analysis for GIS-based landslide susceptibility mapping-A case study of the 2008 Iwate-Miyagi Nairiku Earthquake, Japan. J Japan Landslide Soc 52(2):51-59 (in Japanese with English abstract)

Has B, Maruyama K, Noro T, Nakamura A (2012) An approach of susceptibility analysis for deep-seated landslide induced by earthquake within pre-existing landslide topography using logistic regression. J Japan Landslide Soc 49(1):12-21 (in Japanese with English abstract)

Hayashi K, Hamasaki E, Yagi H, Higaki D (2015) Development of landslide susceptibility mapping model for earthquake-induced landslides based on buffer movement analysis and blunder probability analysis. J Japan Landslide Soc 52(2):60-66 (in Japanese with English abstract)

Higaki D, Hayashi K, Hamasaki E, The Project team of Collaborative Research for River and Erosion Control, Japan Landslide Society, Kanbara J (2015) A report on the collaborative research for river and erosion control by the Japan landslide society and ministry of land, infrastructure, transportation and tourism-Susceptibility mapping of earthquake-induced landslides. J Japan Landslide Soc 52 (2):85-92 (in Japanese)

Kamp U, Growley BJ, Khattak GA, Owen LA (2008) GIS-based landslide susceptibility mapping for the 2005 Kashmir earthquake region. Geomorphol 101(4):631-642

Keefer DK (1984) Landslides caused by earthquakes. Geol Soc Am Bull 95:406-421

Miyagi T, Prasad G B, Tanavud C, Potichan A, Hamasaki E (2014) Landslide risk evaluation and mapping-Manual of aerial photo interpretation for landslide topography and risk management. Reports of the National Research Institute for Earth Science and Disaster Prevention, No 66, pp 75-136 
Rodríguez CE, Bommer JJ, Chandler RJ (1999) Earthquake-induced landslides: 1980-1987. Soil Dynamics and Earthquake Engineering 18(5):325-346

Sugimoto H, Takeshi T, Uto T, Takeshi T, Honma H (2012) Geomorphologic and geologic features of landslides induced by the 2011 Off the Pacific Coast of Tohoku Earthquake, in Shirakawa Hills, Fukushima Prefecture. Earthquake-Induced Landslides: Proceedings of the International Symposium on Earthquake-Induced Landslides. Kiryu, Japan. pp 189-201

Takeuchi K, Yanagisawa Y, Miyazaki J, Ozaki M (2004) 1:50,000 Digital Geological Map of the Uonuma region, Niigata Prefecture (Ver. 1), GSJ Open-file Report, No. 412. https://www.gsj.jp/data/ openfile/no0412/index.html

The Japan Landslide Society (2012) Earthquake-induced landslides, p 302 (in Japanese)

The Project team for Collaborative Research and Development of River and Erosion Control, Japan Landslide Society (2013) Characteristics and their classification of landslides induced by the 2011 Great
East Japan Earthquake. J Japan Landslide Soc 50(2):25-30 (in Japanese)

Yagi H, Sato G, Higaki D, Yamamoto M, Yamasaki T (2009) Distribution and characteristics of landslides induced by the Iwate-Miyagi Nairiku Earthquake in 2008 in Tohoku District, Northeast Japan. Landslides 6:335-344

Yagi H, Yamasaki T, Moriiwa T (2005) Characteristics of landslides triggered by the Niigata Chuetsu earthquake in 2004 with special reference to geology and geomorphology. Proceed Intern'l Symp Landslide Hazard in Orogenic Zone drom the Himalaya to Island Arc in Asia, pp. 407-416, Japan landslide Society

Yalcin A, Reis S, Aydinoglu AC, Yomralioglu T (2011) A GIS-based comparative study of frequency ratio, analytical hierarchy process, bivariate statistics and logistics regression methods for landslide susceptibility mapping in Trabzon. NE Turkey Catena 85(3):274-287

Yokoyama R, Shirasawa M, Kikuchi Y (1999) Representation of topographical features by opennesses. J Japan Soc Photogramm Remote Sens 38(4):26-34 (in Japanese with English abstract)
Open Access This chapter is licensed under the terms of the Creative Commons Attribution 4.0 International License (http:// creativecommons.org/licenses/by/4.0/), which permits use, sharing, adaptation, distribution and reproduction in any medium or format, as long as you give appropriate credit to the original author(s) and the source, provide a link to the Creative Commons license and indicate if changes were made.
The images or other third party material in this chapter are included in the chapter's Creative Commons license, unless indicated otherwise in a credit line to the material. If material is not included in the chapter's Creative Commons license and your intended use is not permitted by statutory regulation or exceeds the permitted use, you will need to obtain permission directly from the copyright holder. 